RU Этнокультурные и языковые стереотипы: особенности взаимодействия

\author{
Холомеенко О. М., Колычева А. С.
}

Аннотация. Цель исследования - выявить особенности языкового выражения интенциональных этнокультурных стереотипов, актуализирующихся или формирующихся в сознании носителей европоцентричной культуры об американском обществе и американских политических лидерах. Научная новизна работы заключается в том, что в ней устанавливается связь между интенциональными этнокультурными стереотипами и языковыми стереотипами на предмет возможности создания определенных идеологических установок в репортажах новостной аналитической программы. В результате была выявлена связь между этнокультурными и языковыми стереотипами, при которой вторые выступают в качестве средства репрезентации первых и способствуют формированию или актуализации этнокультурных стереотипов в картине мира реципиентов.

\title{
EN Ethnocultural and Linguistic Stereotypes: Features of Interaction
}

\author{
Kholomeenko O. M., Kolycheva A. S.
}

\begin{abstract}
The study aims to reveal features of functioning and linguistic expression of intentional ethnocultural stereotypes about the American society and the American political leaders that are actualised or formed in the minds of bearers of the Eurocentric culture. Scientific novelty of the work lies in the fact that it finds connection between intentional ethnocultural and linguistic stereotypes to determine whether it is possible to develop certain ideological attitudes in reports of an analytical news programme. As a result, the researchers have concluded that there is connection between ethnocultural stereotypes and linguistic stereotypes as a means of representing the former that contributes to formation or actualisation of ethnocultural stereotypes in recipients' worldview.
\end{abstract}

\section{Введение}

В современном политическом медиадискурсе стереотипы являются не только одним из ведущих средств оказания влияния на реципиента, но и средством формирования определенного мнения о каком-либо политическом событии или о политическом имидже той или иной персоны. Воздействие на целевую аудиторию происходит в том случае, если есть опора на «когнитивные ассоциации адресата» [9, с. 62]. Актуальность данного исследования обусловлена тем, что политический дискурс, целью которого выступает воздействие на сознание реципиентов и формирование у них конкретного оценочного суждения, эволюционирует в соответствии с изменениями, происходящими в социуме. Соответственно, изменения затрагивают и содержание стереотипных представлений, репрезентация которых происходит в рамках тех или иных манипулятивных стратегий. Среди многочисленных массмедийных источников, освещающих политическую повестку, особый научный интерес представляют те, что, во-первых, транслируются на федеральных каналах, т.е. наиболее известные и озвучивающие основные интересы и позиции государства, во-вторых, используют устную речь, допускающую спонтанное словотворчество и некоторые отклонения от прописанных скриптов.

Материалом для исследования послужили репортажи аналитической информационной передачи «Итоги недели с Ирадой Зейналовой» (в период с октября по декабрь 2020 г.) [6].

В рамках данного исследования мы поставили ряд задач, решение которых приведет к достижению цели: методом сплошной выборки провести отбор языкового материала, содержащего гетеростереотипные представления о политической ситуации в США (эфиры за октябрь-декабрь 2020 г.); выявить и описать идеологическое наполнение гетеростереотипов о политической ситуации в США, функционирующих в современном российском культурном пространстве; проанализировать языковые средства репрезентации интенциональных этнокультурных стереотипов. 
Для решения перечисленных задач в работе использовались следующие методы исследования: метод сплошной выборки; методы дискурсивного и контекстуального анализа; структурно-семантический и классификационный методы.

Теоретической базой исследования послужили труды У. Липпмана [10], В. Н. Телия [16], Н. В. Уфимцевой [18], в которых рассмотрены проблемы сущности стереотипа, его разновидностей, связи между ментальными, этническими и языковыми стереотипами. Также при рассмотрении проблем прецедентности и эмоциональности в речи мы опирались на теоретические основы работ Д. Б. Гудкова [3], И. С. Вацковской [1], И. Г. Горовой [2], В. А. Саблуковой [12], У. В. Смирновой [14].

Практическая значимость работы: материалы исследования могут быть использованы в вузах при освоении курсов по межкультурной коммуникации, теории коммуникации, спецкурсов и спецсеминаров по теоретическому, сравнительному языкознанию.

\section{Краткий обзор теории стереотипа как ментального и языкового явления}

В настоящее время в лингвистике наблюдается стабильный научный интерес к национально маркированным компонентам языка, к проведению многочисленных исследований, содержащих подробное описание языковых единиц, в которых заключены определенные культурные коды, типичные для культуры того или иного народа. Антропоцентрический подход в современном языкознании поставил вопрос о корреляции культуры и языка, открыл новые возможности для проведения исследований в лингвокогнитивной области, для изучения речевых, ментальных и поведенческих стереотипов как средств отражения ментальности, культуры, образа мышления. Кроме того, в рамках межкультурной коммуникации рассматриваются не только глобальные вопросы взаимодействия культур, сущности и функционирования отдельных их компонентов, но и механизмы вербального и невербального воплощения стереотипов, содержащихся в культурной и когнитивной картинах мира.

Стереотип - многогранное явление, он состоит из ментального содержания, из его вербального воплощения, языковой реализации смыслового образа при минимальной затрате когнитивных и поведенческих усилий для достижения определенной коммуникативной цели. Данное понятие может проявлять себя в любых видах человеческой деятельности, следовательно, стереотип является объектом научного интереса в разных областях, и в зависимости от этого варьируется терминологический аппарат, определяющий стереотип и его типологию. Так, выделяются стереотипы расовые, политические, религиозные, социальные, этнические, поведенческие, ментальные, культурные, гендерные, речевые и т.д. [23, с. 70]. Однако следует отметить, что данные термины не являются элементами одной четко структурированной системы, поскольку они генетически не связаны друг с другом, изучаются с позиции разных аспектов, но при этом могут пересекаться и одновременно характеризовать один и тот же феномен.

Н. В. Уфимцева предложила дифференцировать этнические и культурные стереотипы. Согласно концепции данного исследователя, «этнические стереотипы недоступны саморефлексии “наивного” члена общества и являются фактами поведения и коллективного бессознательного, им невозможно специально обучать, а культурные стереотипы доступны саморефлексии и являются фактами поведения, индивидуального бессознательного и сознания, им уже можно обучать» [18, с. 140].

Этнокультурный (этнический) стереотип - это не просто образец восприятия действительности, отличающийся оценочным характером и представленный в языке в качестве устойчивых единиц, но и целый концепт, который, соприкасаясь с другими, формирует картину мира, в которую встроены определенные культурные коды. Такие стереотипы отличаются высокой частотностью повторения, распространенностью, целостностью восприятия и большей устойчивостью.

Природа речевых стереотипов вызывает вопросы у исследователей. Согласно данному подходу последние отождествляются с речевыми шаблонами, устойчивыми языковыми формулами. Так, профессор Л. П. Крысин, посвятивший несколько научных трудов изучению стереотипов с точки зрения лингвистики, отмечает, что их признаки - универсализация и гиперболизация каких-либо реальных явлений. Ученый довольно подробно не только описывает трудности и задачи по исследованию стереотипов-высказываний, предстающие перед исследователями, но и предлагает их решение. Л. П. Крысин подчеркивает, что стереотипы непременно содержат в себе один или несколько объектов оценки, это могут быть анатомические, когнитивные, ментальные, личностные и пр. характеристики людей, национальные традиции, бытовые привычки и многое другое [8, с. 453].

С точки зрения межкультурной коммуникации стереотипы - это в первую очередь национально маркированное явление, содержащее в себе культурные коды и ментальные установки коллектива, в сознании которого они зародились. Однако, как отмечает С. А. Чеканова, порой в других культурах можно встретить их аналоги, и такие случаи нуждаются в более подробном и глубоком изучении, т.к. «совпадая в целом, эти стереотипы могут различаться деталями, имеющими большое значение для успешного общения» [21, с. 265].

При изучении стереотипов с точки зрения их возникновения принято выделять интенциональные и спонтанные стереотипы. Первые создаются намеренно, преследуют вполне ясную цель. Часто интенциональные стереотипы используются для конструирования какого-либо политического или рекламного образа, наполняя его определенными коннотативными и экспрессивными свойствами. Функционирование же спонтанных стереотипов происходит за пределами политического дискурса и никак не связано с преследованием общественных интересов. 
Достаточно активно исследуются особенности функционирования стереотипов в современном политическом дискурсе, в англоязычном политическом дискурсе, а также особенности стереотипов о России $[4 ; 5 ; 11 ; 13 ; 17 ; 20]$.

\section{Авто- и гетеростереотипы в создании политического имиджа}

При работе с эмпирическим материалом мы выбирали только те репортажи аналитической программы, в которых освещалась политическая ситуация в США. В зависимости от объекта содержания мы делили представления, формирующиеся в репортажах, с одной стороны, на содержащие представления этноса или социальной группы о самих себе, с другой стороны, устойчивые представления, сложившиеся у носителей одной культуры о представителях другой.

Так, например, журналист «эксплуатирует» представления американцев о своей миссии на политической арене: «Наверное, лучше сформулировать иначе: неужели он (Трамп), так упорно работавший над своей идеей великой Америки, был уверен, что контролирует всё и всегда?» (эфир от 06.12.2020); «Наверное, это процесс закономерный, потому что мировой американский полицейский со своими проблемами справиться не может...» (эфир от 04.10.2020). В каждой стране есть представление о роли страны в мировом политическом пространстве, в том числе и в США есть доктрина о сильной и независимой Америке, но автор репортажа обращает внимание на просчет Д. Трампа, который обманулся в своих планах. Также иронично представлена и роль «мирового полицейского», которая с трудом дается США, поскольку сказано, что в стране не могут решить внутренние проблемы, но посягают на решение глобальных. Лексемы «великая», «мировой» подчеркивают амбициозность планов политических лидеров Америки. В данном случае реализуется тактика игры «на понижение», целью которой является нивелирование образа сильной страны путем иронического употребления лексем «великая», «мировой».

Авто- и гетеростереотипы в той или иной мере присутствуют в сознании каждого индивида, поэтому при столкновении с человеком, принадлежащим другой культуре и этносу, личность неосознанно склонна анализировать его действия сквозь призму собственного мировосприятия, оценивать неизвестное с точки зрения собственных категорий мышления. Это вполне естественные и закономерные психические процессы, облегчающие интерпретацию и структуризацию поступающей в мозг информации. Люди, как правило, в первую очередь обращают внимание «на те особенности поведения, которые подтверждают уже имеющиеся представления» [22, с. 2], например: «Никакой большой сделки не будет при Трампе, никаких больших поворотов при Байдене, хоть он и занимается отношениями с нами еще со времен Громыко» (эфир от 25.10.2020); «Стремление Трампа захватить весь рынок энергоносителей явно никуда не уйдет, и стремление Байдена доказать, что русские во всем виноваты еще со времен его встречи с Громыко...» (эфир от 01.11.2020). В данных примерах приведено имя А. А. Громыко, одного из политических лидеров СССР 80-90-х гг. В политическом дискурсе неоднократно подчеркивалось, что Д. Байден - опытный политик в отношениях с Россией, история которых начинается еще до распада СССР. Но для реципиентов, на которых рассчитана программа, данная оговорка имеет особый смысл: во-первых, только зритель, знающий, в какое время жил и работал А. А. Громыко, может понять, какие долгие и непродуктивные отношения у Д. Байдена и советских и российских лидеров, во-вторых, журналисты явно намекают на весьма почтенный возраст новоиспеченного президента и, как следствие, снижение его интеллектуальной активности. В данном случае журналист продолжает придерживаться тактики игры «на понижение», упоминая об А. А. Громыко в разных эфирах, стремится закрепить в сознании реципиентов определенный образ президента США.

\section{Языковые особенности репрезентации гетеростереотипов}

Стереотипы отличаются от субъективных единичных умозаключений наличием в соответствующих языковых единицах многократно повторяющихся позитивных или негативных суждений относительно одного объекта, массовым и бессознательным их пониманием. Что касается непосредственно валидного языкового материала, то в качестве него могут служить различные паремиологические единицы, фразеологизмы, «синтаксические конструкции, которые можно интерпретировать как средства обозначения этнических стереотипов» [8, с. 452], например: «Из больницы Дональд Трамп собирался сначала выписываться в футболке с суперменом, но потом передумал - неправильно поймут. Супермен здесь сегодня один, и он то ли срывает ненавистные маски, то ли наоборот, раздает их, спасая американцев» (эфир от 18.10.2020); «Китай, он сейчас, в канун Хэллоуина, еще и страшный скелет в семейном шкафу Байденов» (эфир от 01.11.2020); «Гордость Трампа - соцсети, которые в 16-ом стали оружием его победы, - сегодня вставляют палки в колеса» (эфир от 08.11.2020). Вне контекста фразеологические единицы можно отнести к клишированным формам, которые служат маркером определенной ситуации. В данных примерах использование фразеологизмов привносит негативную оценку, журналисты программы подчеркивают, что оба политических лидера находятся в сложной ситуации: исход выборов не определен, есть сложности у действующего президента, а репутация новоиспеченного не кристально чистая. Тактический прием, связанный с определенным эмоциональным настраиванием, реализуется путем употребления известных носителю русской культуры идиом.

Говоря о сущности речевых стереотипов, нельзя не упомянуть полемику между В. Н. Телия и Ю. С. Степановым. Так, Вероника Николаевна отнесла природу стереотипа к предметной области культуры и определила его сущность как культурную модель репрезентации в знаковой (в т.ч. вербальной) форме представлений, 
включенных в коллективное сознание. Однако Ю. С. Степанов отверг возможность существования непосредственной корреляции между предметными областями языка и культуры. Данные возражения поспособствовали появлению некоторых ценных дополнений. Так, например, В. Н. Телия отмечает: «...в интерпретативном соотнесении языковые знаки обретают культурно значимую функцию и способность выступать как “знаки” языка культуры, как “тела” этих знаков, совместно манифестируя культурные концепты своим планом выражения и планом содержания» [16, с. 238]. Связующим звеном языковых знаков с культурой является интерпретация содержания знаков с учетом их взаимозависимости с культурными концептами, порождающая коннотативные оттенки, которые, как правило, закреплены в словарях в виде помет «одобр.», «неодобр.», «презрит.», «уничижит.»и др. Увидев такие пометы, мы узнаем, как именно расценивается то или иное явление, каков его морально-нравственный облик и т.д. [15, с. 158].

Поскольку стереотипные представления на ментальном уровне являются ценностно ориентированными, они обретают соответствующее материальное оформление, часто реализуясь в языке при помощи экспрессивной и оценочной лексики, например: «Давайте быстро посмотрим рекламу и попытаемся понять, почему война за власть - чаще всего это война без правил, особенно сейчас, когда до американских выборов две недели» (эфир от 18.10.2020); «То, что сейчас происходит в Америке, это больше чем война за умы и голоса, это уже похоже на войну против всех. И традиционный обмен конкурентов обвинениями и угрозами уже тоже больше, чем традиция - оба понимают, что даже победа на выборах может быть только началом войны с большими проблемами, ведь вирус не побежден, и война с ним достанется именно победителю» (эфир от 18.10.2020);

«Американцы ведь явно помнят, что в Киргизии не только наша военная база “Кант”, но когда-то была и их "Манас", и она в момент войны в Афганистане была им очень полезна, а мир снова у красной черты и может снова начать всеобщую войну - лишняя база не помешает» (эфир от 01.11.2020); «Тонкая красная линия это то, что разделяет для американцев все происходящее на до и после выборов» (эфир от 01.11.2020); «Вот она, тонкая линия, которую мы перешагнули, и прекратили доверять друг другу, и вернуться обратно очень сложно» (эфир от 01.11.2020); «И такого ведь не было даже во времена Холодной войны, когда мы друг друга пугали, но за линию не заходили» (эфир от 01.11.2020). В данной подборке примеров лексема «война» в различных сочетаниях обозначает и вооруженную борьбу, и воздействие на кого-либо, и средство достижения своих целей. А лексемы «линия» и «черта» намекают на определенную границу, перейдя которую лидеры США могут навсегда утратить доверие как собственного электората, так и внешних политических партнеров. У реципиентов создается представление о нестабильной обстановке в США как во внутренней, так и внешней политике. В данном случае журналист использует тактический прием, нацеленный на коррекцию модели мира реципиентов, в целом придерживаясь стратегии дискредитации.

Особое внимание уделим прецедентным феноменам в качестве языковых средств репрезентации стереотипов. Как отмечает Т. П. Карпухина, «одним из эффективных приемов речевого воздействия, активно осваиваемых современными средствами массовой информации, является использование категории прецедентности, отсылающей к значимым экстралингвистическим явлениям, получившим языковое выражение, образ которых закреплен в общественном сознании» [7, с. 36].

Прецедентный феномен запускает в сознании носителей языка уникальную цепь ассоциаций, также следует отметить, что сам феномен может приобретать новый смысл в конкретном контексте [19, с. 125].

Используя в своей речи какой-либо прецедентный феномен, автор уже вводит эмоциональную оценку события или ситуации. Изначально прецедентные феномены носят эталонный характер, воспроизводя в сознании носителя определенной культуры источник появления феномена. Другими словами, введение прецедентности в качестве экспрессивного средства является «экономным» способом воздействия на реципиентов, достаточно лишь указать на текст, ситуацию или имя. Это речевое воздействие может носить и манипулятивный характер, например: «Пять миллионов голосов в проблемной для Трампа Джорджии начали подсчитывать вручную по инициативе госсекретаря штата республиканца Раффенспергера, ведь на улицах авторитетные ораторы уже начали взывать к справедливости с броневиков» (эфир от 22.11.2020); «Отрыв в нескольких ключевых штатах, сменяется вес внезапным набором голосов Байденом - и в итоге сдача всех позиций. Одновременно поступают данные о мертвых душах. То за Байдена голосует 118-летний Вильям Бредли, мужчина умер еще 1984-ом...» (эфир от 08.11.2020); «Едва ли Америка услышит в ближайшее время “Я проиграл. Я ухожу" (эфир от 08.11.2020); “Сама песня - это нечто среднее между “не надо печалиться, вся жизнь впереди” и “если с другом вышел в путь - веселей в дороге” (эфир от 18.10.2020); “Заколотите это немедленно!” Люксовые магазины прячут витринные окна перед выборами» (эфир от 01.11.2020). Данные контексты содержат целый калейдоскоп феноменов: прецедентная ситуация (речь В. И. Ленина на броневике) и прецедентные высказывания («Я устал. Я ухожу» - из речи Б. Ельцина о снятии с себя полномочий президента), прецедентные тексты (поэма Н. В. Гоголя «Мертвые души», строчки из песен советского периода, название передачи канала СТС «Снимите это немедленно!», отсыл к роману Дж. Оруэлла «1984»). Культурная картина мира журналистов и зрителей позволяет актуализировать в общих фоновых знаниях указанные явления, сопоставить эталон и обозначенную в репортаже ситуацию и понять интенции журналистов.

\section{Заключение}

Выводы, к которым мы пришли в результате решения поставленных в исследовании задач: отбор языкового материала, представленного в новостных эфирах, позволяет проследить основные тенденции актуализации 
гетеростереотипных представлений о политической ситуации в США для создания определенного имиджа политического противника в репортаже; стратегии реализации манипулятивного воздействия на реципиентов репортажей аналитической программы основаны на реализации тактик эмоционального настраивания, коррекции модели мира, статусно-ролевой игры «на понижение», данные тактики для усиления воздействующего потенциала используют имеющиеся и формируют новые стереотипные представления о политических противниках; связь между этнокультурными и языковыми стереотипами можно обозначить следующим образом: этнокультурный стереотип, функционируя в сознании носителей определенной культуры, имеет особенности языкового выражения. Это могут быть лексемы оценочного характера, употребленные в качестве метафоры, способствующие переосмыслению ситуации, расширению представления о ней, также в качестве средств выражения стереотипов могут быть фразеологические единицы, привносящие оценочный компонент в контекст, но наиболее экспрессивным средством выступают прецедентные феномены, являющиеся в некоторых случаях средством манипуляции.

В качестве перспектив дальнейшего исследования можно обозначить проведение исследований по установлению корреляций между этнокультурными стереотипами и языковыми и речевыми клише и штампами, что позволит создать перечень языковых единиц, обслуживающих, например, определенную коммуникативную ситуацию. Такого рода работы представляются полезными при взаимодействии со стереотипами в различных сферах, начиная с преподавания иностранного языка, заканчивая анализом языка политического и массмедийного дискурса.

\section{Источники | References}

1. Вацковская И. С. Прецедентное имя в политическом дискурсе // Studia Linguistica XVII. Язык и текст в проблемном поле гуманитарных наук. СПб.: Политехникасервис, 2008. С. 338-342.

2. Горовая И. Г. Роль прецедентных феноменов в формировании вторичной языковой личности // Вестник Оренбургского государственного университета. 2015. № 11 (186). С. 65-70.

3. Гудков Д. Б. Прецедентные феномены в текстах политического дискурса // Язык СМИ как объект междисциплинарного исследования: учеб. пособие. М.: МГУ, 2003. С. 141-161.

4. Жарина О. А. Заголовок как средство создания образа государства в зарубежных СМИ // Балтийский гуманитарный журнал. 2019. Т. 8. № 2 (27). С. 235-237.

5. Жарина О. А., Инюточкина А. Д. Реализация стратегии манипулирования в политическом дискурсе английских СМИ: лексический уровень // Балтийский гуманитарный журнал. 2018. Т. 7. № 4 (25). С. 55-58.

6. Итоги недели с Ирадой Зейналовой [Электронный ресурс]. URL: https://www.ntv.ru/peredacha/Itogi_nedeli/ (дата обращения: 29.05.2021).

7. Карпухина Т. П. Прецедент и его роль в медиарепрезентации личности президента США Д. Трампа (на материале статей об импичменте) // Политическая лингвистика. 2020. № 2 (80). С. 35-43.

8. Крысин Л. П. Этностереотипы в современном языковом сознании: к постановке проблемы // Философские и лингво-культурологические проблемы толерантности: коллективная монография / отв. ред. Н. А. Купина, М. Б. Хомяков. М.: ОЛМА-ПРЕСС, 2005. С. 450-455.

9. Кудряшов И. А., Чернышева А. Ю. Проблема фреймирования трагического события в зоне военнополитической напряженности в репортажном дискурсе идеологически альтернативных СМИ // Актуальные проблемы филологии и педагогической лингвистики. 2021. № 1. С. 60-72.

10. Липпман У. Общественное мнение / пер. с англ. Т. В. Барчуновой; Фонд «Обществ. мнение». М.: Ин-т Фонда «Обществ. мнение», 2004. 382 с.

11. Русских Л. В., Фомина С. В. Формирование политических стереотипов в СМИ // Вестник Южно-Уральского государственного университета. Серия «Социально-гуманитарные науки». 2015. Т. 15. № 1. С. 116-117.

12. Саблукова В. А. Суггестивные механизмы использования национально-прецедентных феноменов в дискурсе конфликта (на материале реалий русской лингвокультуры в англоязычных СМИ/) // Вестник Челябинского государственного университета. 2014. № 16 (345). С. 124-127.

13. Синицина Т. А. О роли стереотипов в межкультурной коммуникации // Актуальные вопросы современной лингвистики: материалы 4-й Всероссийской научно-практической конференции, посвященной 85-летию МГОУ и 70-летию ИЛиМК / отв. ред. М. Н. Левченко. М., 2017. С. 60-66.

14. Смирнова У. В. Прецедентные феномены как инструмент манипуляции // Вестник Иркутского государственного лингвистического университета. Серия «Филология». 2008. № 2. С. 131-136.

15. Степанов Ю. С., Проскурин С. Г. Константы мировой культуры: алфавиты и алфавитные тексты в период двоеверия. М.: Наука, 1993. 160 с.

16. Телия В. Н. Русская фразеология: семантический, прагматический и лингвокультурологический аспекты. М.: Школа «Языки русской культуры», 1996. 288 с.

17. Токарева О. С. Этнокультурные стереотипы: откуда они берутся и как к ним относиться? // Иностранные языки: лингвистические и методические аспекты. 2017. Вып. 39. С. 204-209.

18. Уфимцева Н. В. Русские: опыт еще одного самопознания // Этнокультурная специфика языкового сознания / отв. ред. Н. В. Уфимцева. М.: Эксперимент, 1996. С. 139-162.

19. Фащанова С. В. Ключевые прецедентные феномены в контексте национального менталитета (на материале радиодискурса) // Вестник Московского университета. Серия 22. Теория перевода. 2014. № 4. С. $124-132$. 
20. Федулова М. Н. Функционирование этнокультурных стереотипов в американском политическом дискурсе (на материале английского языка) // Казанская наука. 2019. № 5. С. 102-105.

21. Чеканова С. А. Роль стереотипов в межкультурном общении // Современная наука: актуальные проблемы теории и практики. Серия «Гуманитарные науки». 2017. Вып. 12. С. 263-265.

22. Чеснокова Л. В. Стереотипы в межкультурной коммуникации [Электронный ресурс] // Концепт. 2015 . № 4. C. 1-7. URL: https://e-koncept.ru/2015/15107.htm (дата обращения: 03.06.2021).

23. Щекотихина И. Н. Стереотип: аспекты и перспективы исследования // Вестник Ленинградского государственного университета им. А. С. Пушкина. 2008. № 5 (19). С. 69-80.

\section{Информация об авторах | Author information}

RU Холомеенко Ольга Михайловна ${ }^{1}$, к. филол. н. Колычева Алина Сергеевна ${ }^{2}$

1,2 Южный федеральный университет, г. Ростов-на-Дону

EN Kholomeenko Olga Mikhailovna ${ }^{1}, \mathrm{PhD}$

Kolycheva Alina Sergeevna ${ }^{2}$

${ }^{1,2}$ Southern Federal University, Rostov-on-Don

${ }^{1}$ kholol2012@yandex.ru, ${ }^{2}$ amarilsiz@mail.ru

\section{Информация о статье | About this article}

Дата поступления рукописи (received): 27.04.2021; опубликовано (published): 30.06.2021.

Ключевые слова (keywords): этнокультурные стереотипы; языковые стереотипы; вербализация; прецедентность; политический дискурс; ethnocultural stereotypes; linguistic stereotypes; verbalisation; precedence; political discourse. 